\title{
Drug debate expands
}

\section{Washington \& Paris}

A US congressman last week accused the French drug manufacturer Roussel-Uclaf and US government officials of giving in to pressure from anti-abortion activists and withholding the abortion drug RU-486 from researchers studying cancer and other diseases.

Although initial hopes for RU-486 as the perfect at-home abortifacient have dimmed as the realities of its use became apparent (several clinical visits and companion treatments are required to use it safely and effectively), it has become a promising candidate for other medical applications. At a hearing last week of the subcommittee on regulation of the US House of Representatives Small Business Committee, researchers testified that RU486 therapy could result in treatments for breast cancer, a rare glandular disorder known as Cushing's syndrome, other hormonal disorders and perhaps even hypertension and AIDS.

But because the Food and Drug Administration (FDA) imposed a ban last year on the commercial import of the drug, and Roussel-Uclaf has been reluctant to provide it to researchers, much of the research on non-abortion uses for RU-486 has ground to a halt, said subcommittee chairman Ron Wyden (Democrat, Oregon). "As a result of FDA's RU-486 policies, anti-abortion politics, and the manufacturer's business decisions, Amer-

\section{UK RESEARCH COUNCILS}

\section{AFRC looks overseas}

\section{London}

BASKING in the glow of a 44 per cent increase in funding from the European Communities this year, the UK Agricultural and Food Research Council (AFRC) has gone multilingual in its annual report, for the first time including summaries in French, German and Spanish. The change is not just cosmetic, says acting AFRC secretary Brian Jamieson. The council is expanding international collaboration at all levels, including increased involvement of North American and European scientists in its peer-review process, he says.

The other research councils have no plans to follow the AFRC's multilingual approach in their annual reports, but stress that they are nevertheless committed to increasing earnings from overseas. Annual reports are aimed primarily at the Secretary of State for Education and Science, a Natural Environment Research Council (NERC) spokesman says, and NERC uses carefully targeted brochures to market its science to overseas customers.

Peter Aldhous icans now suffering from horrible illnesses will not have the hope of cures they had before the import ban was imposed", Wyden charged.

Several researchers testified that they had been denied the drug by FDA or Roussel-Uclaf, or told by the company that sufficient supplies of RU-486 could not be guaranteed. In a memorandum to subcommittee members, Wyden said that Roussel-Uclaf officials had said that they were not willing to risk opposing the US government on distribution of the drug for fear that an anti-abortion backlash could endanger worldwide RU-486 approval by the World Health Organization, which depends heavily on US financial support.

But FDA officials said that the agency had intended only to thwart personal use - not legitimate clinical research - and that including researchers in the ban had been a mistake. Once a scientist has obtained special FDA approval — as with any drug that has not been approved for commercial distribution - "getting the drug becomes the responsibility of the researcher and the drug company", says FDA spokesman Jeff Nesbit. And although no Roussel-Uclaf representative testified at the hearing, a company official said in an interview that it, too, has no intention of obstructing good research, as long as it is not related to abortion.

"So long as the protocol appears interesting to our scientific committee and fits in with our own developments, we will supply the drug", said Ariel Mouttet, marketing director for RU-486 at Roussel-Uclaf in Paris.

In the case of one US scientist, Katherine Horwitz, a breast cancer researcher at the University of Colorado who testified that she had been denied permission by the FDA to import the drug for a clinical trial, Mouttet said, "If [she] writes to us with a protocol and asks for RU-486, and our scientific committee decides it is an interesting study, she will get the drug". When researchers have been denied the drug, she said, it was because their protocols had been found scientifically unworthy, or were linked to abortion research.

George Chrousos, a researcher at the National Institutes of Health who is studying Cushing's syndrome, says he is now more optimistic that he will be able to secure enough RU-486 from RousselUclaf to allow his research to continue. Although he had previously received enough of the drug to continue his work for several years, he expects to run out in a few months without a new supply. Recently, he says, he has been unable to get an assurance from the company that it would make RU-486 available to him. "It's been quite uncertain. They have not refused, but they haven't given an answer", he says. But public outcry over the endangered research may have shifted the balance, he says.

Mouttet said that Roussel-Uclaf has no plans to commercialize the drug in the United States, or to allow clinical trials of the drug as an abortifacient to go ahead. (It still cannot be bought, even in France, for personal use of any kind.) But the company is taking part in US clinical trials where RU-486 is used in the treatment of endometriosis and meningioma, she said.

Mouttet also expressed surprise at the claims that are being made for RU-486 in breast cancer research. "We are only at the clinical research stage. There is absolutely no evidence that the drug is effective in such cases." She said it was "scandalous" to suggest that RU-486 could be used in the treatment of AIDS. "There is absolutely no evidence, not even theoretical". Such claims only served to raise the hopes of the sick "and to make Roussel-Uclaf look wicked", she said.

Meanwhile, Roussel-Uclaf is maintaining its "step by step" approach to commercializing the drug as an abortifacient elsewhere, Mouttet said. A decision by the UK Department of Health is expected in January, following an application made this year. If Britain agrees to authorize the drug, Roussel-Uclaf will probably target Scandinavia, where abortion is legal and noncontroversial. So far, 50,000 pregnancies have been terminated by using RU-486. Christopher Anderson \&

Peter Coles

\section{SCIENTIFIC PUBLISHING}

\section{Coping with copyright}

\section{London}

To ease the minds of its US customers, who must obey strict copyright laws, the Yorkshire-based British Library Document Supply Centre (BLDSC) has decided to charge a copyright fee on top of its normal duplication costs for scientific manuscripts. The library, which is the world's largest supplier of photocopies of articles from scientific journals, says the move will help to clear up what has been "an uneasy relationship" with scientific publishers on the copyright issue.

The new scheme, which will start in April 1991, is not compulsory - scientists will be exempt from the charge if they sign, as at present, a declaration that the copy is for personal use only. But those paying the copyright fee (about $£ 1$ per paper) will be able to distribute copies more widely. US drug companies, among BLDSC's most important customers, support the move, as it will allow them to store copies of important research papers in their own libraries, or pass copies around large research groups, says Graham Cornish, the library's copyright officer. Peter Aldhous 